\title{
Health-Related Counseling of Elderly People in the Domestic Setting
}

\section{Christa Them ${ }^{1 \star}$, Eva Schulc ${ }^{2}$}

${ }^{1}$ Department of Nursing Science, UMIT, Hall in Tirol, Austria.

${ }^{2}$ Department of Gerontology and Demographic Development, UMIT - Private University of Health Sciences, Medical Informatics and Technology, Hall in Tirol, Austria.
*Corresponding author

Christa Them, Professor, Department of Nursing Science, UMIT, Hall in Tirol, Austria, Tel:+43(0)-508648-3891; E-Mail: christa.them@umit. at.

Submitted: 09 Jan 2017; Accepted: 19 Jan 2017; Published: 25 Jan 2017

\begin{abstract}
Introduction: In accordance with the wish of elderly people to live independently in their own homes for as long as possible, appropriate consideration should be granted to the promotion of elderly people's independence from a social and health-political viewpoint.
\end{abstract}

Aim: The aim was to assess the functional health of elderly people living at home and thus, based on individual problem areas and resources, the need for provision of health-related counseling.

Method: In the framework of an exploratory cross-sectional study, entitled "Preventive Senior Counseling in Tyrol", a multidimensional nursing assessment through self-reporting was performed on 345 people aged $70+$. Derived from the individual assessed problem areas and resources, the registered nurses decided which of the recommended and standardized 14 counseling topics were relevant for the individual participants.

Results: Initially, the sample of elderly people was analyzed in relation to their belonging to one of four functional health-related risk groups (e.g. risk of falls etc.). Many people - irrelevant if they belonged to any of the risk groups or none at all - showed a high degree of independence as well as a multitude of health-related impairments. All of these findings highlighted a pronounced need for counseling, although on different topics.

Discussion: The preventive home visit, as offered here, was used as a counseling instrument for elderly people in the domestic setting. A serious need for counseling on issues that support independent living at home derives from the nursing assessment of the participants' problem areas and resources.

Keywords: functional health; 70+ year olds living at home; risk group; counseling,

\section{Introduction}

The vast majority of elderly people want to be able to live independently at home for as long as possible [1]. In this context it is primarily important that elderly people live a largely autonomous life with as little dependency as possible on outside help. If they are dependent on outside help that they are able to use the necessary means of support in such a way that independent living in the main areas of life is still possible [2]. To meet this wish, appropriate consideration should be granted to the promotion of elderly people's independence from a social and health-political viewpoint. The preventive home visit is a means to postpone the dependency on care, to make full use of preventive potentials and to minimize health risks [3]. Furthermore, self-care competence has to be promoted, besides support and care by relatives as well as by social services.

Taking into consideration the above mentioned aspects, we conducted a cross-sectional study, entitled "Preventive Senior
Counseling in Tyrol", which focused on preventive home visits to people aged 70+ living at home in Tyrol.

Aims

Within the scope of preventive home visits, registered nurses evaluated the self-reported functional health of $70+$ year olds living at home by means of a nursing assessment and provided counseling on the promotion of independent living, based on identified problem areas and resources in relation to functional health.

\section{Definition of Terms}

Independent Living: in old age in this context is defined as multidimensional concept which is based on a biopsychosocial approach including the multifarious living backgrounds of seniors, their abilities and present difficulties as well as environmentrelated factors and their interrelations [4].

Functional Health: A person is functionally healthy if (a) his/ her body functions (including mental functions) correspond to the functions of a healthy human being (concept of body functions 
and structures), (b) he/ she is able to do all the things which can be expected from a person without health problems (concept of activities), (c) he/ she can master his/ her life in all life situations which are important to this individual in a way which can be expected from a person without impairments of body functions, body structures or activities (concept of participation in all life situations) [5].

Austrian Care Allowance System: In Austria, people's need for nursing care has been assessed based on the seven levels of care allowance since 1993. Care need is a demand for care and assistance which must amount to at least 65 hours per month and "will presumably last for at least six months." The assessment of the care level is part of the care allowance assessment and is primarily body- and functionality-related [6].

Ethical Aspects

The study was forwarded to the Research Committee for Scientific and Ethical Questions (RCSEQ) at UMIT and was approved prior to the start of the study.

\section{Methods \\ Research Questions}

The following two research questions were defined with a focus on possible risk groups of elderly people living at home as there is evidence that

- The risk of being dependent on care is higher for people aged 80 and older [7].

- A higher frequency of falls has an influence on a possible institutionalization [8].

- The risk of care dependency [7] and thus the risk of institutionalization is higher for people who receive care allowance or people who are already in need of care (either by nursing relatives or professional services) $[6,9]$.

Research Question 1: What are the functional health-related problem areas and resources of people aged 70+ living at home, who are 80 or older, fall-prone as well as dependent on nursing care and/ or receive care allowance?

Research Question 2: Which need for counseling on functional health-related topics can be derived from the results of the assessment of people aged 70+ living at home, who are 80 or older, fall-prone as well as dependent on nursing care and/ or receive care allowance?

\section{Sample and Recruiting}

Recruitment of the study participants is based on a convenience sample of 345 people aged $70+$ living at home in Tyrol. Inclusion criteria were age $70+$ at the time of the study, no cognitive impairments, a signed written declaration of consent as well as no legal guardian. The nurses who collected the data during the study "Preventive Senior Counseling in Tyrol" were all registered nurses with at least three years' work experience in mobile care and nursing [10].

\section{Study Design}

For this study we chose an exploratory quantitative cross-sectional study design.
Instrument - Nursing Assessment incl. Consultation Form

The nursing assessment was a self-reported questionnaire based on the theoretical model of the WHO classification and the patient questionnaire STEP (Standardized Assessment of Elderly People in Primary Care) $[5,11]$. The nursing assessment consisted of two parts: (1) contextual factors - socio-demographic data, current use of nursing care, care allowance level - (2) functionality of a person - body functions (physical, emotional-psychic \& motion-related health status) - activities including two standardized instruments, Barthel Index (BI) and IADL Index [12,13]. The computer-assisted two-part nursing assessment lasted 45 minutes on average.

\section{Counseling Through Standardized Consultation Forms}

The consultation form with 14 topics, on the one hand, was based on the results of the project „Preventive Home Visits to Elderly People - Projektmobil" and on the other hand, was based on the consultation form used in the project „Senior Counseling in Tennengau, Salzburg“ $[4,14]$. For the conduct of the present study, this consultation form was adapted to the local conditions by registered nurses in an expert conference. The nursing assessment and the subsequent counseling were computer-assisted and designed to suggest the registered nurses appropriate topics with standardized contents for each of the identified problem areas and resources of the $70+$ year olds. The registered nurse then decided on the type of counseling needed to support the independent living of each individual participant.

\section{Data Analysis}

The computer-assisted data collection allowed for automatic data conversion for further statistical analysis in SPSS 20.0 Version for Windows. All statistical analyses were performed with SPSS 20.0 for Windows. Descriptive data analysis was performed corresponding to the respective scale level through measures of location and dispersion. As a measure of association for calculating the risk of falling, we used odds ratios (OR) with 95\% CI [15]. We chose a significance level of $\alpha=5 \%$.

\section{Selected Results}

Sample

The total sample included 345 people aged $70+$ living at home. The major part of the participants was female $(70 \%)$. The average age was $83.51 \%$ of the people were widowed, $84 \%$ had children -2.4 on average. $50 \%$ of the participants were living alone.

\section{Results with Respect to Possible Risk Groups}

Risk Group -Age: $81 \%$ of the 345 participants were 80 and older.

Risk Group - People who had a Fall, Which Means They Come or go Down Involuntarily From a Standing Position to The Floor or a Lower Position: $47 \%$ of 344 people aged 70+ stated that they had a fall at least once during the last year [16]. Asked for the fall frequency, $40 \%$ said that they fell,, once", $25 \%$ said that they fell , twice "and 35\% said that they fell , more than twice "during the last year. Among the group of people who had a fall $(\mathrm{n}=162), 16$ risk factors could be identified. People whose BI indicated," a dependency on care "or who expressed motionrelated impairments and were unsatisfied with their health status had the highest risk of suffering a fall. 
Risk Group - Recipients of Care Allowance: $47 \%$ of the participants stated that they received care allowance. Most of them were in care level $2(39 \%)$, followed by $25 \%$ in care level $1,20 \%$ in care level 3 and $16 \%$ in care levels 4 to 6 .

Risk Group - People in Need of Nursing Care by Relatives (Informal Care) as well as by External Institutions (Home Help): $40 \%(n=136)$ of the interviewed $70+$ year olds said that they were in need of nursing care. Out of this $40 \%$, the higher percentage (54\%) were being taken care of by „relatives“ (=informal care), $29 \%$ by ,external institutions "and $17 \%$ by ,external institutions“ as well as by ,relatives“.

The majority of $70+$ year olds living at home are being taken care of by their own children (mostly by the daughters with $57 \%$ ), followed by spouses in $26 \%$ and children-in-law in $17 \%$ of the cases.

\section{Provided Counseling}

In total, 326 out of 345 people aged $70+$ received 641 consultations on health- and nursing-related topics and 785 consultations on financial, legal or socio-institutional topics. Most frequently, consultations were provided on the offers by municipal social services $(60 \%)$, care allowance $(58 \%)$, behavior in emergency situations $(45 \%)$, safe housing $(40 \%)$, acquisition of aids $(36 \%)$ as well as on specific exercises and mobility improvement (31\%).

\section{Counseling with Respect to Risk Groups}

The following statements solely refer to significant findings in relation to the need for counseling of: people aged $80(>)$ vs. people aged $<80$; people who had a fall vs. people who did not have a fall, people who receive care allowance vs. people who do not receive care allowance, as well as people in need of nursing care vs. people not in need of nursing care.

Risk Group - Age: $80+$ year olds had significantly $(p=.033)$ more counseling on safe housing than people aged 70-79. Conversely, people aged 70-79 had significantly $(p=.025)$ more counseling on care allowance and on group activities provided by municipal social services $(\mathrm{p}=.021)$.

Risk Group - People who had a Fall: People who had a fall had highly significantly $(\mathrm{p}<.001)$ more counseling on specific exercises and mobility improvement and significantly $(p=.036)$ more counseling on safe housing than people who did not have a fall.

Risk Group - Care Allowance Recipients: It became evident that people who did not receive care allowance had highly significantly $(p<.001)$ more counseling on care allowance than care allowance recipients.

Risk Group - People in Need of Nursing Care: People in need of nursing care had highly significantly $(p<.001)$ more counseling on specific exercises and mobility improvement as well as on medication intake. Furthermore, they had significantly more counseling on the acquisition of aids, medical evaluation as well as food and drink than people not in need of nursing care.

Planned Interventions Subsequent to Counseling Subsequent to counseling, 17 possible interventions were planned individually with the 70+ year olds living at home (e.g. assistance in filing an application for care allowance, home adaptions, arrangement of home care services...). It was also discussed if the $70+$ year olds should implement those measures themselves or if relatives and/ or other external institutions should do so. Moreover, the participants could refuse certain measures.

As an example, in the following the results of the risk group care allowance recipients vs. non-care allowance recipients are presented.

Risk Group Care Allowance Recipients vs. Non-CareAllowance Recipients: Among the $47 \%(n=161)$ of care allowance recipients, we identified $60 \%(n=96)$ who were eligible to apply for a care allowance payment increase. In most cases, the participants $(n=95$, $59 \%$ ) said that their relatives would apply for the payment increase. It was interesting to note that six people refused to apply.

As to the non-recipients of care allowance $(53 \%, n=184)$, we identified $112(61 \%)$ who were eligible to submit an initial application for care allowance. Also in these cases, the majority of participants $(76 \%, \mathrm{n}=86)$ requested that their relatives should file the application. Also in this group participants refused to apply $(n=9)$.

\section{Discussion}

The results in relation to the self-assessed functional health of people aged $70+$ showed a multitude of health problems associated with assistance and care, like diseases, sleeping problems, pain, motoric deficits etc [5]. and highlighted serious need for counseling on health- and nursing-related, socio-institutional as well as financial and legal issues in order to support independent living at home. With respect to possible risk groups of elderly people (which are people: (a) aged $80+$, (b) who had a fall in the last year, (c) who receive care allowance, (d) in need of assistance and nursing care) it became evident that both groups of $70+$ year olds (people who belonged to one or more of these risk groups vs. people who did not belong to any of these risk groups) had a serious need for counseling on functional health, although to different levels. The preventive home visit, as offered in the setting of this study, was used as a counseling instrument. Instead of a general training program, a counseling program was conducted, similar to the studies by Sherman et al. and which ought to be the basis for targeted support planning $[17,18]$.

\section{Outlook Work Science}

Based on the results of the study, a systemic integration of preventive home visits including counseling and intervention planning was recommended to the respective political representatives. In 2014, preventive home visits were legally incorporated into the service catalogue of mobile care services by a resolution of the Federal Government of Tyrol and have been offered since then free of charge to all people aged $70+$ living at home in Tyrol.

In conclusion, it should be noted that the purpose of the present study with its study design primarily was to make the $70+$ year olds aware of their life and health situation, with the possible consequence to adjust their living situation to the age-specific changes and to activate possible resources. We cannot tell whether the provided counseling and interventions have led to sustained 
improvements of the physical, psychological and social well-being of the $70+$ year olds as no efficacy testing was conducted $[19,20]$.

\section{References}

1. Schulc E, Them C, Müller G, Knitel-Grabher E, Mantovan F (2014) Selbstständige Lebensführung von zu Hause lebenden älteren Menschen unter besonderer Berücksichtigung der Lebensformen. Eine explorative Querschnittsstudie. Pflegewissenschaft 6: 340- 352 .

2. Kruse A (2005) Selbstständigkeit, bewusst angenommene Abhängigkeit, Selbstverantwortung und Mitverantwortung als zentrale Kategorien einer ethischen Betrachtung des Alters. Zeitschrift für Gerontologie und Geriatrie 38: 273-287.

3. Weidner F (2005) Experten-Hearing Präventiver Hausbesuch imAlter-Dokumentation. Bonn, Germany: Bundesvereinigung für Gesundheit e.V., Arbeitsgruppe 3 Gesund altern des Deutschen Forums Prävention und Gesundheitsförderung.

4. Gebert A, Schmidt C, Weidner F (2008) Präventive Hausnbesuche bei Senioren: Projekt mobil; der Abschlussbericht. (D.I. für angewandte P.E.V., Ed.) Präventive Hausbesuche bei Senioren: Projekt mobil; der Abschlussbericht. Germany: Schlütersche.

5. WHO (2005) ICF - International Classification Functioning, Disability and Health.Ed.: DIMDI - WHO's Collaborating Centre for the Family of International Classifications, Germany.

6. Austrian Federal Law Gazette 110/1993, in its current version $2015, \S 4(1,2)$.

7. Hoogerduijn J G, Schuurmans M J, Duijnstee MSH, de Rooij SE,Grypdonck MFH (2007) A systematic review of predictors and screening instruments to identify older hospitalized patients at risk for functional decline. Journal of Clinical Nursing 16: 46-57.

8. Seematter-Bagnoud L, Wietlisbach V, Yersin B, Büla C J (2006) Healthcare utilization of elderly persons hospitalized after a noninjurious fall in a Swiss academic medical center. Journal of the American Geriatrics Society 54: 891-897.

9. Riedl M, Mantovan F, Them C (2012) Being a nursing home resident--a challenge for one's identity. Pflege Z 65: 280-285.

10. Schulc E, Pallauf M, Wildbahner T, Them C (2016) Präventive
Hausbesuche zur Unterstützung einer selbständigen Lebensführung älterer Menschen im häuslichen Setting - Eine Querschnittstudie. Zeitschrift für Geronotologie und Geriatrie 49: 526-534.

11. Sandholzer H, Hellenbrand W, von Renteln-Kruse W, Van Weel C, Walker P, et al. (2004) STEP - Europäische Leitlinie für das standardisierte evidenzbasierte präventive Assessment älterer Menschen in der medizinischen Primärversorgung. Deutsche Medizinische Wochenschrift 129: 183-226.

12. Mahoney F, Barthel Dw (1965) Functional Evaluation: The Barthel Index. Md State Med J 14: 61-65.

13. Lawton MP, Brody EM (1969) Assessment of older people: self-maintaining and instrumental activities of daily living. Gerontologist 9: 179-186.

14. Schulc E, Them C (2011) Seniorenberatung im Tennengau Bedarfs- und Akzeptanzanalyse. Austria. Unveröffentlichter Endbericht des Departments für Pflegewissenschaft und Gerontologie der UMIT.

15. Backhaus K, Erichson B, Plinke W, Weiber R (2011) Multivariate Analysemethoden. Eine anwendungsorientierte Einführung (13.Auflage ed.). Berlin, Heidelberg: Springer Berlin Heidelberg.

16. Kellog (1987) The prevention of falls in later life. A report of the Kellogg International Work Group on the Prevention of Falls by the Elderly. Dan Med Bull 34 Suppl 4: 1-24.

17. Sherman H, Forsberg C, Karp A, Törnkvist L (2012) The 75-year-old persons' self-reported health conditions: a knowledge base in the field of preventive home visits. J Clin Nurs 21: 3170-3182.

18. Behm L, Ivanoff SD, Zidén L (2013) Preventive home visits and health-experiences among very old people. BMC Public Health 13: 378.

19. Imhof L, Naef R, Mahrer-Imhof, Petry H (2011) SpitexPlus: Assessment und fortgeschrittene Pflegeinterventionen für zuhause lebende alte Menschen und ihre Familien. Pflege 24: 43-56.

20. Luck T, Motzek T, Luppa M, Matschinger H, Fleischer S, et al. (2013) Effectiveness of preventive home visits in reducing the risk of falls in old age: a randomized controlled trial. Clinical Interventions in Aging 8: 697-702.
Copyright: (02017 Christa Them. This is an open-access article distributed under the terms of the Creative Commons Attribution License, which permits unrestricted use, distribution, and reproduction in any medium, provided the original author and source are credited. 